\title{
Association of antithrombin-III and platelet count with pregnancy induced hypertension
}

\author{
Purnima Dey Sarkar, Sonal Sogani*
}

Department of Biochemistry, M.G.M. Medical College, Indore-452001, M.P., India

Received: 24 July 2013

Accepted: 4 August 2013

\section{*Correspondence:}

Sonal Sogani,

E-mail: sonal.sogani246@gmail.com

(C) 2013 Sarkar PD et al. This is an open-access article distributed under the terms of the Creative Commons Attribution Non-Commercial License, which permits unrestricted non-commercial use, distribution, and reproduction in any medium, provided the original work is properly cited.

\begin{abstract}
Preeclampsia is referred to as the "disease of the theories" because of the multiple hypotheses proposed to explain its occurrence. Despite considerable research, the causes of preeclampsia remain unclear. It is multifactorial in nature and recent research has focused on the measurements of various prothrombotic markers for detection of latent clotting pathway activation. This study was undertaken to determine the changes in the levels of plasma Antithrombin -III (AT-III) and platelet count in preeclamptic women and its comparison with healthy non-pregnant women and normal pregnant women and its correlation with severity of disease in order to evaluate if it can be used as a marker for severity of pregnancy induced hypertension $(\mathrm{PIH})$. This is the case-control hospital based study carried in the Department of Biochemistry M.G.M. Medical College and associated M.Y. Hospital. Indore (M.P.). 40 women with preeclampsia in the third trimester of pregnancy constituted the study group. The study group was further divided into two subgroups as mild and severe preeclampsia. Age and gestational age matched 23 healthy non -pregnant and 28 normal pregnant women were taken as a control group. There were no significant differences among the three groups in age and body mass index (BMI) but significantly higher differences in gestational age, systolic and diastolic blood pressure was observed. When compared with control groups (healthy non-pregnant and normal pregnant women), the levels of AT-III in preeclamptic group was significantly lower. Although there was no significant difference in the levels of AT-III between healthy non-pregnant and normal pregnant women. The platelet count between healthy nonpregnant and normal pregnant women showed statistically significant difference whereas statistically higher significant difference was observed when comparison was done between healthy non-pregnant women and preeclamptic women and normal pregnant women and preeclamptic women. It was concluded from the study that the reduction of platelet count and AT-III are the main predictors to predict and monitor the severity of the condition.
\end{abstract}

Keywords: Preeclampsia, Antithrombin-III (AT-III), Platelet count, Pregnancy induced hypertension (PIH), Hypercoagulability, Thrombocytopenia

\section{INTRODUCTION}

Preeclampsia is a clinical manifestation characterized by hypertension, proteinuria and edema that occurs after $20^{\text {th }}$ week of pregnancy. ${ }^{1}$ It is an idiopathic multisystem disorder of pregnancy affecting about $5-8 \%$ of all pregnancies and is a major cause of maternal, fetal and neonatal mortality and morbidity. ${ }^{2,3}$ Although the etiology of preeclampsia remains unknown, it is suggested that preeclampsia is associated with intervillous and spiral artery thrombosis, vascular endothelial damage and abnormalities of coagulation, leading to inadequate maternal, fetal and placental circulation. ${ }^{4}$ Immunological adaptation disorders, abnormal increase of vasoconstrictor tone, nutritional factors, and genetic factors are some other theories. ${ }^{5}$

Normal pregnancy is associated with changes in the haemostatic mechanism with increased levels of the coagulation factors and suppressing of fibrinolysis. ${ }^{6}$ 
Therefore normal pregnancy is considered to be the state of hypercoagulability and hypercoagulation is more pronounced during the third trimester. Pregnancy is a state of silently ongoing intravascular coagulation at least in the uteroplacental circulation. ${ }^{7}$ These modification of the coagulation system is to ensure rapid and effective control of bleeding from the placental site and prevent fatal hemorrhage during delivery and puerperium. ${ }^{8}$

Preeclampsia is a pathophysiological disorder specific to pregnancy and characterized by vasoconstriction and hypercoagulability. ${ }^{9}$ In women with preeclampsia, intravascular coagulation frequently coexists leading to thrombus formation in the uteroplacental unit and other maternal organs and thrombocytopenia or hemoconcentration are frequently associated with low AT-III activity in pathological conditions. The balance between coagulation and anticoagulation systems is shifted towards coagulation, and thus there is a thrombotic tendency. ${ }^{10}$ In preeclamptic pregnancies, the coagulation is generally activated with more decreased fibrinolysis, with platelet activation and consumption, promoting of thrombin formation and fibrin formation and destruction. ${ }^{11}$ There is a shift in the haemostatic balance towards a pro-thrombotic state, together with changes in endothelial and placental function. ${ }^{12}$ Recently measurements of various prothrombotic markers have become available and the measurement of Antithrombin III was found to be a sensitive parameter for detection of latent clotting pathway activation. ${ }^{13}$

\section{METHODS}

This case control study was conducted in the Department of Biochemistry M.G.M. Medical College and associated M.Y. Hospital. Indore. The subjects were pregnant women clinically diagnosed as preeclampsia during third trimester (28-40 weeks) with the age 18-35 years (GROUP-C) visiting obstetrics OPD and wards of MY Hospital, The study group was further divided into two subgroups. It comprised of 25 mild preeclamptic pregnant women (SUBGROUP C1) and 15 severe preeclamptic pregnant women (SUBGROUP C2) on the basis of blood pressure, (both systolic and diastolic) proteinuria and pathological edema, which is the diagnostic criteria of preeclampsia. As a control group 23 healthy nonpregnant women (GROUP-A) and 28 normal pregnant women (GROUP-B) were taken. The normal pregnant women were also in the third trimester (28-40 weeks) of their pregnancy with the age 18-35 years. Group A women were normotensive, nonproteinuric and in child bearing age of 20-40 years. Inclusion criteria for women included in the study were: should not be using any kind of oral contraceptives, anticoagulant drugs, should be non-smokers and non alcoholics and exclusion criteria was: past history of diabetes, systemic or endocrine disorder, chronic infection, chronic renal disease and hypertension (in group A \& B only), women in the labour pains, were excluded from the study.
Preeclampsia was diagnosed according to American college of Obstetrics and Gynecology (ACOG) criteria: a blood pressure higher than $140 / 90 \mathrm{~mm} \mathrm{Hg}$ and proteinuria more than $300 \mathrm{mg} / 24 \mathrm{hr}$ were observed on at least two occasions more than $6 \mathrm{hrs}$ apart after the $20^{\text {th }}$ weeks of pregnancy. Preeclampsia were classified as severe if diastolic blood pressure increased to at least $110 \mathrm{mmHg}$, proteinuria $>5000 \mathrm{mg}$ per day and the presence of headache, visual disturbances, epigastric pain, oliguria, elevated LFT, elevated RFT, thrombocytopenia.

For Hematological parameter (platelet counts), blood samples were collected in EDTA tubes and plasma was separated after centrifugation for 5-10 minutes at 3000 rpm within one hour of the venepuncture. Hematological parameter (platelet counts) was performed on cell counter PCN-201(N). For Coagulation parameter (AT-III), blood was placed into test tubes containing $1 \mathrm{ml}$ of $3.8 \%$ sodium-citrate. Centrifugation of these specimens was done for ten minutes at room temperature and at $2500^{\times} \mathrm{g}$. The level of AT-III was studied using the fully automatic Coagulometer equipment (Diagnostic Stago STA Compact; France). The results were expressed as mean \pm $\mathrm{SD}$ and groups were compared using ANOVA.

Statistical analysis was carried out by using SPSS software, version 20. The level of significance was set at $<0.05$.

\section{RESULTS}

The anthropometric factors of the study groups are summarized in table 1 .

Maternal age and body mass index (BMI) were not significantly different between the groups $(p>0.05$, Table 1). Gestational age, systolic and diastolic blood pressures were significantly higher in preeclamptic groups as compared to healthy non-pregnant and normal pregnant women $(\mathrm{p}<0.0001$, Table 1$)$. The same when compared between mild and severe preeclamptic groups, it was found to be significantly higher in severe preeclamptic group ( $\mathrm{p}<0.0001$, Table 1$)$.

The mean values of platelets for the healthy nonpregnant, normal pregnant and preeclamptic groups are given in Table 2. Statistically significant difference was observed when comparison was done between healthy non-pregnant and normal pregnant groups $(\mathrm{p}<0.05)$. However, when the comparison was done between healthy non-pregnant and preeclamptic groups and normal pregnant and preeclamptic groups the values was significantly higher in healthy non-pregnant and normal pregnant groups as compared to that of preeclamptic group $(\mathrm{p}<0.0001, \mathrm{p}<0.0001$, respectively). When the mean values of mild and severe preeclamptic pregnant women were compared, it was found to be lower in the latter group and the difference comes to be statistically significant $(\mathrm{p}<0.05)$. 
The mean values of AT-III for the healthy nonpregnant, normal pregnant and preeclamptic groups are given in Table 2. There was no significant difference between the healthy non-pregnant and normal pregnant women ( $>0.05$, Table 2). When the preeclamptic patients were compared to the healthy non-pregnant and normal pregnant groups, the AT-III value was found to be lower in the former group with statistically higher significant differences $(\mathrm{p}<0.0001, \mathrm{p}<0.0001$, respectively). When the mean values of mild and severe preeclamptic pregnant women were compared, the decrease in AT-III in severe preeclamptic women was highly significant compared to that of mild preeclamptic pregnant women $(\mathrm{p}<0.0001)$.

Table 1: Comparison of anthropometric factors of study subjects.

\begin{tabular}{|lllllllllll|}
\hline \multirow{2}{*}{$\begin{array}{l}\text { Anthropometric } \\
\text { factors }\end{array}$} & \multicolumn{1}{c}{ Group A } & \multicolumn{3}{c}{ Group B } & \multicolumn{3}{c|}{ Group C1 } & \multicolumn{3}{c|}{ Group C2 } \\
\cline { 2 - 10 } & Mean & \pm SD & Mean & \pm SD & Mean & \pm SD & Mean & \pm SD & \\
\hline Age $(\mathrm{yrs})$ & 22.91 & 3.26 & 22.46 & 2.74 & 23.64 & 3.32 & 23.26 & 3.12 & 0.572 \\
\hline BMI $\left(\mathrm{Kg} / \mathrm{m}^{2}\right.$ ) & 24.26 & 1.39 & 24.06 & 1.47 & 24.38 & 1.98 & 24.15 & 1.87 & 0.912 \\
\hline Gestational age (wks) & ----- & ----- & 38.64 & 3.17 & 35.76 & 1.73 & 33.46 & 1.78 & $<0.0001$ \\
\hline $\begin{array}{l}\text { Systolic blood pressure } \\
\text { (mm of Hg) }\end{array}$ & 113.30 & 8.25 & 115.35 & 5.07 & 139.6 & 5.38 & 168.6 & 17.5 & $<0.0001$ \\
\hline $\begin{array}{l}\text { Diastolic blood pressure } \\
\text { (mm of Hg) }\end{array}$ & 71.73 & 5.65 & 75 & 5.77 & 95.36 & 5.76 & 113.33 & 12.9 & $<0.0001$ \\
\hline
\end{tabular}

Table 2: Comparison of AT-III and platelets of study subjects.

\begin{tabular}{|llllllllll|}
\hline \multirow{2}{*}{$\begin{array}{l}\text { Clinical } \\
\text { parameters }\end{array}$} & \multicolumn{2}{l}{ Group A } & \multicolumn{3}{c}{ Group B } & \multicolumn{3}{c|}{ Group C1 } & \multicolumn{2}{c|}{ Group C2 } & p value \\
\cline { 2 - 12 } & Mean & \pm ISD & Mean & \pm SD & mean & \pm SD & Mean & \pm SD & \\
\hline AT-III & 94.76 & 6.96 & 94.60 & 10.3 & 78.32 & 3.09 & 70.84 & 6.9 & $<0.0001$ \\
\hline Platelet count & 3.48 & 0.90 & 2.43 & 0.65 & 1.98 & 0.41 & 1.47 & 0.32 & $<0.0001$ \\
\hline
\end{tabular}

\section{DISCUSSION}

Preeclampsia is a leading cause of fetal and maternal morbidity and death. There is increasing evidence that abnormal enhancement of coagulation activity is involved in the pathogenesis of preeclampsia. Out of all hematological changes, thrombocytopenia is the most common hematological abnormality found in about 10 $25 \%$ of those with preeclampsia/ eclampsia. ${ }^{14}$ Although the pathogenesis of thrombocytopenia in preeclampsia is not clear, but it is suggested that it may be due to endothelial damage and the peripheral consumption. The life span of platelet reduced to 3-5 days and the altered platelet membrane accelerates its aggregation and destruction. ${ }^{15}$ The results from our study concluded that preeclamptic groups as compared to healthy non-pregnant and normal pregnant groups showed significantly lower platelet count with the statistical difference of $\mathrm{p}<0.0001$. The difference between mild and severe preeclamptic groups were statistically significant $(p<0.05)$. These results were in consistent with the results given by S. Mohapatra et $\mathrm{al}^{16}$ and Mindora Onisai, AnaMaria Vladareanu, Horia Bumbea et al. ${ }^{17}$
AT- III is plasma protein which inactivates all activated clotting enzymes, except factor VIIa, and is thought to be main physiologic inhibitor of blood coagulation. ${ }^{18}$ It belongs to the class of serine protease inhibitors. ${ }^{19}$ Several hypothesis have been suggested for the reduction of AT-III associated with preeclampsia. Firstly ,because AT-III inactivates thrombin by forming $1: 1$ molecular complex with it and in vivo generation of thrombin antithrombin complexes which is molecular marker of activation of the blood coagulation system. Secondly due to reduced hepatic synthesis there is a reduction of ATIII. Thirdly the extrinsic loss is observed in nephrotic patients. ${ }^{20}$ The major cause is enhanced consumption due to generalized fibrin deposition in maternal vascular tree. $^{21}$ In our study, the plasma AT-III levels of normal pregnant women as compared to healthy non-pregnant women were lower but the difference was not statistically significant. This was in consistent with the study done by Maryam-Sadat Hosseini et al. ${ }^{22}$ In our study and in the other studies, ${ }^{23,24}$ performed on preeclamptic pregnant women; AT-III levels were significantly lower than those of healthy non-pregnant and normal pregnant women. Our study reveals that as compared to mild preeclamptic group, the lower levels of AT-III in severe preeclamptic 
group was observed and the difference was statistically high $(\mathrm{p}<0.0001)$.

\section{CONCLUSION}

In conclusion, preeclamptic women have decreased platelet counts and more pronounced deficiencies of AT-III as compared to healthy non-pregnant and normal pregnant women. These findings suggest that there is an excessive hypercoagulable state in preeclampsia and are involved in pathogenesis of the condition. Thus the reduction of platelet counts and AT-III are the main predictors to predict and monitor the severity of the condition.

\section{REFERENCES}

1. F. Gary Cunningham, Kenneth J. Leveno, Steven L. Bloom, John C. Hauth, Dwight J. Rouse, Catherine Y. Spong. Williams OBSTETRICS- $23^{\text {rd }}$ ed. New York, NY: McGraw-Hill; 2010:706-756.

2. WHO, 2004. Bethesda, MD. Global Burden of Disease for the Year 2001 by World Bank Region, for Use in Disease Control Priorities in Developing Countries, National Institutes of Health: WHO. Make every mother and child count. World Health Report, 2005, Geneva: World Health Organization, 2005. $2^{\text {nd }}$ ed.

3. Stekkinger E, Zandstra M, Peeters LL, Spaandernen ME. Early-onset preeclampsia and the prevalence of postpartum metabolic syndrome. Obstet Gynaecol 2009 Nov; 114(5):1076-84.

4. Roberts JM, Cooper DW. Pathogenesis and genetics of preeclampsia. Lancet 2001; 357:53-6.

5. Lopez-Jaramillo P, Casas JP, Serrano N. Preeclampsia: from epidemiology observation to molecular mechanisms. Brazil J Med Biol Res 2001; 34:1227-35.

6. Stirling Y, Woolf L, North WR, Seghatchian MJ, Meade TW. Haemostasis in normal pregnancy, Thromb Haemost 1984; 52:176-182.

7. Ludwig H. Hemorrhagic disorders in pregnancy. Ther Umsch 1999; 56:608-615.

8. Bremme KA. Haemostatic changes in pregnancy. Bests Pract Res Clin Haematol 2003; 16(2):153-8.

9. Matsuda Y, Tomosugi T, Maeda Y et al. Cerebral magnetic resonance angiographic findings in severe preeclampsia. Gynecol Obstet Invest 1995; 40:249252.

10. Tomado S, Tamura T, Sudo Y et al. Effect of obesity on pregnant maternal hemodynamic changes. Am J Perinatol 1996; 13:73-78.

11. Helimann L, Rath W, Pollow K. Hemostatic abnormalities in patients with severe preeclampsia. Clin Appl Thromb Hemost 2007; 13(3):285-291.

12. Sibai B, Dekker G, Kupferminc M. Preeclampsia. Lancet 2005; 365(9461):785-799.
13. Heimberger N, Pelzer H. Determination of human thrombin-antithrombin iii complex by enzyme immunoassay. Folia Haematol (Leipz) 1988; 115:269-73.

14. Baha M Sibai. Hypertension in pregnancy. In: S.G. Gabbe, J.R. Niebyl, J.L. Simpson editors, Obstet. Normal and Problems of Pregnancies. $3^{\text {rd }}$ Eds. New York: Churchill Livingstone; 1996:p.935-991.

15. Moran P, Davidson JM. Clinical management of established preeclampsia. Baillieres Best Pract Res Clin Obstet Gynecol 1999; 13:77-93.

16. S. Mohapatra, B.B, Pradhan, U.K. Satpathy, Arati Mohanty and J.R.Pattnaik. Platelet estimation; Its prognostic value in pregnancy induced hypertension. Indian Journal Physiol Pharmacol 200; 51(2):160-16.

17. Minodora Onisai, Ana-Maria Vladareanu, Horia Bumbea, Mihai Ciorascu, Ciprian Pop et al. A study of the hematological picture and of platelet function in preeclampsia-report of a series of cases. A Journal of Clinical Medicine 2009;4(4):326-337.

18. Sen C, Madazli R, Kavuzlu C, Ocak V, Tolun N. The value of antithrombin -III and fibrinectin in hypertensive disorders of pregnancy. J Perinat Med 1994;22:28-38.

19. Travis J and Salvesen GS. Human plasma proteinase inhibitors. Annual Review of Biochemistry 1983; 52:655

20. Terao T, Kobayashi T, Imai N, Oda H, Karasawa T. Pathological state of the coagulatory and fibrinolytic system in preeclampsia and the possibility of its treatment with AT III concentrate. Asia Oceanic J Obstet Gynecol. 1989;15:25-32.

21. Paternoster D, Stella A, Simioni P, Trovo S, Plebani $\mathrm{P}$, Girolami A. Clotting inhibitors and fibronectin as potential markers in preeclampsia. Int $\mathbf{J}$ Gynecol Obstet 1994;47:215-221.

22. Maryam-Sadat Hosseini, Parviz Gharehkhani, Maryam Sadeghi. Association of inherited thrombophilia and antiphospholipid syndrome with severe preeclampsia. Iranian Journal of Reproductive Medicine 2007;5(4):183-186.

23. Cengiz Demir and Imdat Dilek. Natural coagulation inhibitors and active protein resistance in preeclampsia. Clinics (Sao Paulo) 2010 Nov; 65(11):1119-1122.

24. M. Thamrin Tanjung, H. Djafar Siddik, Herman Hariman, Stephen C.L .Koh. Coagulation and Fibrinolysis in Preeclampsia and Neonates. Clin Appl Throm Hemost 2005 Oct; 11(4):467-73.

DOI: $10.5455 / 2320-1770.1 j r \operatorname{cog} 20130927$

Cite this article as: Sarkar PD, Sogani S.

Association of antithrombin-III and platelet count with pregnancy induced hypertension. Int J Reprod Contracept Obstet Gynecol 2013;2:398-401. 